\title{
The Influence of Writing Beliefs on Two Chinese EFL University Students' Use of Peer Feedback: An Ecological Perspective
}

\author{
Ma Jingjing (Corresponding author) \\ Department of English, Hang Seng Management College \\ Hang Shin Link, Siu Lek Yuen, Shatin, N.T., Hong Kong \\ E-mail: maggiema@hsmc.edu.hk
}

Received: 13-12-2015

Published: 01-05-2016
Accepted: 07-03-2016

doi:10.7575/aiac.ijalel.v.5n.3p. 247
Advance Access Published: March 2016

URL: http://dx.doi.org/10.7575/aiac.ijalel.v.5n.3p.247

\begin{abstract}
Despite the increasing popularity of peer feedback in EFL writing classrooms, little research has been conducted to explore how individual factors such as learner beliefs may influence L2 students' use of peer feedback. From an ecological perspective (van Lier, 2000, 2004), this exploratory case study investigated the extent of peer feedback use by two purposefully-chosen Chinese EFL university students and how their use of feedback was mediated by learner beliefs, a salient factor that emerged from the study. Detailed qualitative data were collected from multiple sources: written documents, stimulated recall, semi-structured interviews, and classroom observations. The findings indicated that the two students integrated peer comments selectively into their revision across two tasks. The selective use of peer feedback was found to be mediated by writing beliefs related to qualities of good English expository writing, to the importance of word limit and to student reviewer roles. Seen from an ecological perspective (van Lier, 2000, 2004), these writing beliefs were employed by the students to create affordances to mediate the use of feedback while some of these beliefs were shaped by local classroom affordances (Peng, 2011). Pedagogical implications of the findings are also discussed.
\end{abstract}

Keywords: Chinese EFL university students, use of peer feedback, writing beliefs, ecological perspective, affordances

\section{Introduction}

During the past several decades, L2 writing classrooms have witnessed the growing popularity of peer feedback as a component of process-oriented writing instruction (Lockhart \& Ng, 1995; Tsui \& Ng, 2000; Zhao, 2010). To ascertain the effect of peer feedback on student revision, researchers have investigated different dimensions of peer-mediated revision (e.g. writing quality after revision, types of revision, focus of revision, etc.). Among these dimensions, the extent of peer feedback use has been identified as an important aspect to explore, particularly in studies that compare student use of teacher and peer feedback (Paulus, 1999; Tsui \& Ng, 2000; Yang, Badger, \& Yu, 2006; Zhao, 2010). While it is not surprising to find that student writers tend to be selective in peer feedback use (Paulus, 1999; Tsui \& Ng, 2000; Yang et al., 2006), little is known about factors that may affect students' selective use of peer feedback, which essentially links peer comments as input with peer-mediated revisions as output.

Using an ecological perspective (van Lier, 2000, 2004), this paper reports on an exploratory case study that investigates the extent of peer feedback use by two purposefully-chosen students in a university EFL writing course in China, one of the under-represented EFL contexts in feedback research (Lee, 2014), and how their selection of peer feedback was mediated by their beliefs about EFL writing, a salient factor among others that emerged from the study. By focusing on the factor of learner beliefs, an individual factor often ignored in feedback research (Storch \& Wigglesworth, 2010), this paper contributes to our understanding about the influence of students' writing beliefs on their use of peer feedback, and provides insights into helping students make informed decisions in selecting peer feedback to improve writing.

\section{Literature review}

\subsection{L2 students' selective use of peer feedback}

As an important dimension of peer-influenced revision, the extent to which L2 students incorporate peer feedback into their revision has attracted much attention from researchers (Paulus, 1999; Yang et al., 2006; Zhao, 2010). Both ESL and EFL students, including Chinese EFL students, have been found to use peer feedback selectively. For example, 11 ESL undergraduate students in Paulus' (1999) study used 51\% of peer feedback; 18 Chinese EFL students in Zhao's (2010) study used $46 \%$ of peer comments; while 6 EFL Chinese students in Yang et al.'s (2006) study employed 76\% of peer feedback. As can be seen from the different proportions of peer feedback incorporated into writing, the L2 students in the aforementioned studies did not use all the feedback received from their peers. The selective use of peer feedback seems to indicate that the students are exercising ownership or authorial control over their writing as independent decision makers (e.g. Tsui \& Ng, 2000; Villamil \& de Guerrero, 1998). 
While it has been acknowledged that L2 students tend to use peer feedback selectively (Paulus, 1999; Yang et al., 2006; Zhao, 2010), much still needs to be known about what factors motivate them to use (or not to use) peer feedback; empirical studies of this have been sparse. A review of the literature suggests the potentially important influence of the following two categories: contextual factors and characteristics of peer feedback. An example of contextual factors may be peer feedback training, which has been found to enable a group of Taiwanese EFL students to increase the use of peer feedback from $42 \%$ before training to $77 \%$ after training (Min, 2006). Regarding the characteristics of feedback, Min (2003) has shown that her Taiwanese student participants did not use peer feedback due to its vagueness. Although more studies are needed to gauge different factors under each category as mentioned above, learners' role in interpreting and using feedback needs special attention in feedback research (Hyland, 2010). For example, Storch and Wigglesworth's (2010) case study of two highly proficient Indonesian ESL students found that the students rejected teacher feedback that did not resonate with their beliefs about language use. These beliefs thus enable the students to exercise volitional control or agency in their use of teacher feedback. Given the role of learner beliefs in enabling students to exercise agency in their language learning and to define their own learning contexts (Barcelos, 2003; Storch \& Wigglesworth, 2010), it seems important to approach learners' role in interpreting and using feedback (peer feedback included) from the perspective of learner beliefs. Studies related to learner beliefs about SLA are reviewed in the next section.

\subsection{Learner beliefs about SLA}

Broadly defined as "opinions and ideas that learners... have about the task of learning a second/foreign language" (Barcelos, 2003, p.1), learner beliefs about SLA have been found to greatly influence students' L2 learning. For example, learner beliefs about language learning may affect L2 students' language learning strategies (Riley, 1997), as well as their interpretation of language learning situations, subsequent decision-making and actions (Woods, 2003). As indicated by Storch and Wigglesworth (2010), learner beliefs may also lead students to reject teachers' corrective feedback that is not in line with their beliefs about language use. When it comes to learning of L2 writing, learner beliefs about or perceptions of L2 writing or revisions have been found to influence students' writing or revision strategies (Lei, 2008; Porte, 1997; Victori, 1999). The above-mentioned studies have suggested how learner beliefs may mediate learner actions. However, there may be dissonance between beliefs and actions due to contextual factors (Barcelos, 2003).

Beliefs about SLA have traditionally been regarded as a mental trait, a subcomponent of metacognitive knowledge (Wenden, 1987). In addition to the cognitive dimension, however, beliefs have also been recognized to have a social dimension, that is, they are contextual and dynamic (Barcelos, 2003). Firstly, beliefs are socially constructed and shaped by social and cultural contexts (Barcelos, 2003; Riley, 1997). For example, one important shaping influence on learner beliefs is teacher instruction, with teachers playing the role of significant others to reinforce or help construct learner beliefs (Barcelos \& Kalaja, 2011; Navarro \& Thornton, 2011). The effect of teacher instruction may sometimes be further traced to teacher beliefs (Allen, 1996). For instance, Allen (1996) found that teacher beliefs about English language learning, conveyed through learning activities and classroom instruction, made the beliefs of the Libyan ESL student in her study resemble those of the teacher. Secondly, beliefs are dynamic, that is, they are subject to contextual influence and are amenable to change (Allen, 1996; Riley, 2009). For example, Riley (2009) demonstrated the shifts in beliefs about English language learning of 661 first-year Japanese university students over a nine-month period, and the shifts in some student beliefs may be due to the influence of teacher beliefs.

With the social nature of learner beliefs, a contextual approach (Barcelos, 2003) has been used to explore this topic, in contrast to a normative or a metacognitive approach that mainly treats beliefs as a mental trait (e.g. Wenden, 1987). Taking an emic perspective, the contextual approach intends to understand L2 students' beliefs in specific contexts and regards their beliefs as embedded in their contexts (Barcelos, 2003). This study acknowledges the contextual and dynamic nature of learner beliefs by adopting a contextual approach.

\subsection{An ecological perspective on language learning}

An ecological perspective on language learning (van Lier, 2000, 2004) challenges the input-output metaphor of language learning. Rather, it replaces the concept of input with that of affordance, which refers to "a particular property of the environment that is relevant... to an active, perceiving organism [i.e. an L2 learner] in the environment" (Van Lier, 2000, p.252). The environment is full of language that offers learning opportunities to active learners. Immersed in an environment full of meaning potential, the learners may transform the meaning potential of the environment into linguistic affordances and use them for linguistic actions. In short, instead of regarding learning as happening exclusively inside one's head, the ecological perspective emphasizes the interaction between the learner and the environment while not denying cognitive processes (van Lier, 2000). It reflects a situative (or contextualized), rather than a cognitive, perspective on learning. To acknowledge the contextual nature of students' use of and revision after peer feedback, this paper adopts an ecological perspective to investigate L2 students' use of peer feedback.

To create linguistic affordances from the environment, L2 learners may rely on their beliefs. For instance, Kim's (2013) case study of two Korean immigrants in Toronto showed that one of participants, Sandra, was able to use her beliefs to transform her L2 learning environment into meaningful affordances, which positively affected her English learning. However, the other participant, Paul, had less effective beliefs which failed to enable him to transform his learning environment into affordances, and this negatively influenced his English learning. 
Learner beliefs not only play a role in creating affordances for L2 learning from the environment, but have also been found to be mediated by classroom affordances. As demonstrated by Peng's (2011) case study of a Chinese first-year college student, classroom affordances, that is, "classroom environment that offers meaning ...potential for learning" (p.316) (e.g. teaching practice, learning tasks, lesson goals, etc.) constructed and reconstructed the student's beliefs about English learning over a period of seven months. Due to different classroom affordances, the student's beliefs fluctuated across different situations.

From an ecological perspective (van Lier, 2000, 2004), when it comes to using peer feedback for revision, learner beliefs are likely to help students create affordances (i.e. feedback considered to be useful) from the environment (i.e. all feedback that can be used for revision), thus influencing use of feedback. Moreover, effective learner beliefs may enable students to create appropriate affordances while less effective beliefs may fail to do so. Learner beliefs may also be subject to the influence of local classroom affordances.

\subsection{Research questions}

Based on the above literature review, the following research questions were pursued in the study:

RQ1. To what extent do the selected Chinese EFL university students incorporate peer feedback into their revisions?

RQ2. How do learner beliefs mediate the use of peer feedback and what shapes such beliefs?

\section{Method}

\subsection{Research design}

Adopting a contextual approach to learner beliefs (Barcelos, 2003), this study used a case study approach to gain an indepth understanding of the research questions. At the beginning of the semester, the research purpose was made clear to all 18 students in an English expository writing course that used peer feedback in a large research Chinese university. Based on the willingness to participate and English writing proficiency, one advanced learner and one intermediate learner were chosen to ascertain the extent to which these two students used peer feedback and the influence of possible factors, for example learner beliefs, on their use of peer feedback. These two students' writing proficiency was determined by the grades they had received for the first writing task, and these grades were consistent with the final grades they had obtained for the English expository writing course. The grades received by the students for the first writing task showed that most of them possessed an advanced or intermediate level of English writing ability, and this was also reflected in the selected students.

\subsection{Participants}

Background information on the two student participants is summarized in Table 1. Pseudonyms are used to protect their identities. Both were third year non-English major students aged 20, with approximately 12 years of English learning experience. The students had started to learn English writing formally in Senior III in high school in preparation for the National Matriculation English Test (NMET). After gaining admission into the university, the students had attended different English courses (e.g. Intermediate Level of English Writing, Intermediate Level of English Interpretation) based on university requirements and individual needs so that they could earn the 12 English-course-related credit points required for university graduation. Both students had experienced providing and/or receiving informal peer feedback on English speaking or writing assignments before.

Table 1. Background information on case study students

\begin{tabular}{llll}
\hline Name & Gender & Major & Writing proficiency \\
\hline Tan & F & Biology & Advanced \\
Xiang & F & Optical Science and Engineering & Intermediate \\
\hline
\end{tabular}

The teacher participant, Professor Zhang (pseudonym), had over 26 years of English teaching experience and had taught the English expository writing course for 2 years at the time of the study. As an experienced instructor, he willingly participated in the study and did not seem to be intimidated by my presence as researcher.

\subsection{Research context}

The study was carried out in a 16-week credit-bearing elective course on English expository writing. A process approach to writing was adopted, and there were altogether four "writing cycles". In each cycle, the students were required to brainstorm ideas for a writing topic, produce a first draft, offer feedback on peers' texts, revise the draft based on peer feedback, and submit a second draft for teacher feedback and evaluation. Further revision after teacher feedback was optional. Due to limited class time, the peer feedback activity was conducted outside the class at a time convenient to the students, who came from different departments and had different time tables. The teacher assigned different student reviewers to student writers for each peer feedback task. Then student reviewers had to supply typed comments on peers' writing, and student writers had to respond to and revise based on typed peer feedback without any face-to-face interaction with the reviewers. Although the student writers knew who their reviewers were, they had not known one another before enrolling in this course. The peer feedback was typed using Microsoft Word, and the soft copy of the commented texts was returned to the student writers for revision. The teacher instructed the students to use a peer evaluation form (Appendix A) to evaluate writing and he briefly introduced each concept in the form before the 
first peer feedback activity. According to the teacher, the form reflected the course assessment criteria, which encompassed various concepts in the categories of language, content and organization. No other peer feedback training was conducted.

The students attended the writing class once a week and each class lasted one-and-a-half hours. Different ways of essay development (e.g., illustration, cause and effect, comparison and contrast) and important concepts of English writing (e.g., coherence, topic sentence, thesis statement) were taught in the class. While a total of four writing tasks were assigned during the semester, only the second and third tasks were chosen for this study because the pilot study conducted in the previous semester had indicated that these two tasks could generate in-depth information with regard to the research questions. The second writing task (the illustration essay) required students to use specific examples to illustrate that modern people are more gullible and superstitious than were people in the Middle Ages, while the third writing task (the cause-and-effect essay) required students to explore the reasons why no single Chinese had won any Nobel Prize before ${ }^{1}$. The word limit was 440 words.

\subsection{Data collection}

Data were collected from multiple sources: written documents, stimulated recall, student and teacher interviews and classroom observations. To answer RQ1, documents were collected and stimulated recall was conducted. Documents included the first drafts of writing assignments, peer comments and revised drafts. They were used to gauge the students' use of peer feedback. Textual analysis of peer feedback and revisions made in response to it were then triangulated with data derived from the stimulated recall. The use of stimulated recall could provide a window on the students' processing of peer feedback when they revised without any interaction with peers, particularly decisions concerning peer feedback use and the subsequent revision. An analysis of stimulated recall data, together with the aforementioned written documents, could offer an accurate picture of peer feedback use. The stimulated recall was carried out within three days after the students' peer-mediated revision. The peer feedback the students had received and the revisions they had made were displayed on the computer screen, serving as stimuli (Gass \& Mackey, 2000). To collect responses from the students systematically, a set of instructions (Appendix B) was provided before the recall. I also emphasized to the students that they should recall what they were thinking during the revision rather than explaining their thoughts at the time of the recall. The stimulated recall was verbalized in Mandarin, the native language shared by the students and me, and was audio-recorded.

To answer RQ2, at the beginning of the course, baseline interviews about the students' writing experience were conducted, in which the students articulated their pre-existing writing beliefs. A semi-structured interview was conducted after each stimulated recall of peer-mediated revision to understand factors that could potentially affect the students' selection of peer feedback. In the post-stimulated recall interviews, the students referred to their writing beliefs as one major influence on the use of peer feedback for revision and elaborated on these beliefs. All student interviews were conducted in Mandarin and were audio-recorded. Moreover, the stimulated recall data also turned out to be a good source for understanding the influence of writing beliefs on the students' use of peer feedback. To understand student beliefs in the context being investigated, weekly observation of the writing class was carried out, with field notes taken during observation and developed into full notes afterwards. Classroom observation of teacher instruction was triangulated with teacher interviews concerning classroom practice and related teacher beliefs. For the purpose of the study, writing beliefs are defined as perceptions about the task of learning English writing.

\subsection{Data analysis}

All interview and stimulated recall data were transcribed verbatim and translated into English. The student and teacher participants were then presented with the translation to check its accuracy. To answer RQ1, the peer feedback on each of the student essay was divided into feedback points, which included "symbols and marks in the margins, underlining of problems, and complete corrections, as well as more detailed comments and suggestions" (Hyland, 1998, P. 261). Usable feedback points were further distinguished based on the students' own views regarding the potential of peer feedback for revision, as reflected in the stimulated recall data. For example, the peer feedback that changed the word "proven" to "confirmed" was coded as usable because the stimulated recall data suggested that the student treated it as revision-oriented by considering whether to use it in revision. The comment "I really appreciate some of your ideas and vivid examples..." was coded as not usable because the student did not consider that it had the potential for revision. Since the students did not follow all usable feedback points, the first and revised drafts were compared to identify the usable feedback points acted upon by the students for revision. The result of textual analysis was triangulated with the stimulated recall data. Then the percentage of usable feedback points that were acted upon to the total number of usable feedback points was calculated to determine the extent to which the students integrated peer feedback into their revision for each task (Table 2).

To answer RQ2, a constant comparative analysis (Glaser \& Strauss, 1967) of the semi-structured interviews, field notes and stimulated recall was performed. Categories were developed and themes about the possible influence of various factors on students' use of peer feedback were formulated. It turned out that the influence of writing beliefs emerged as a salient theme. Once the themes were developed, they were repeatedly tested against data for refinement.

\subsection{Trustworthiness}

Measures taken to ensure the trustworthiness of the case study included member checks and triangulation. Member

\footnotetext{
${ }^{1}$ At the time of the study, no Chinese had won any Nobel Prizes before.
} 
checks (Lincoln \& Guba, 1985) were carried out by presenting the participants with my interpretations of the data and soliciting their opinions after data analysis. Triangulation of methods was also employed to strengthen the credibility of the case study. Although a small-scale exploratory study like this is subject to criticism for its lack of generalizability, it is still possible for readers to make naturalistic generalizations (Lincoln \& Guba, 1985).

\section{Findings}

\subsection{The extent of peer feedback use}

Table 2 summarizes the extent of feedback use by the two students across tasks, with the total number of usable peer feedback points for each task shown in the last row. Tan incorporated $62.5 \%$ and $63 \%$ of usable peer feedback points for the two tasks respectively. Xiang followed $63.2 \%$ of usable peer feedback points for the second task (illustration essay) but used a far higher percentage (i.e. 96.4\%) for the third task (cause-and-effect essay).

Table 2. The extent of peer feedback use

\begin{tabular}{lllll}
\hline & Tan & Tan & Xiang & Xiang \\
& Task 2 & Task 3 & Task 2 & Task 3 \\
\hline Usable feedback enacted upon (\%) & 62.5 & 63 & 63.2 & 96.4 \\
$\begin{array}{l}\text { Total number of usable feedback } \\
\text { points }\end{array}$ & 16 & 27 & 19 & 81 \\
\hline
\end{tabular}

\subsection{Influence of writing beliefs}

Three types of writing beliefs were found to influence the two students' selective use of peer feedback, including beliefs about qualities of good English expository writing, about the importance of word limit and about student reviewer roles. The influence of each type of beliefs is illustrated in the following, based on each student's use or non-use of a particular peer comment or correction.

\subsubsection{Beliefs about qualities of good English expository writing}

Tan's and Xiang's pre-existing beliefs about qualities of good English expository writing were found to affect their selection of peer feedback. For example, Tan believed that "good writing should be concise." In response to the peer correction for the illustration essay that changed her original phrase from "in spite of the time that passed since the 1700 's" to "in spite of hundreds years of development", she incorporated this feedback into her revision. She recalled, "OK, I think his correction is good ...I do find that my sentence was not so concise." She further explained in the poststimulated recall interview, "I would check whether my peer's corrections or comments made my sentence more concise or more complex. If my sentence became more complex, I did not consider it necessary to revise the sentence according to his or her suggestion." The data from the stimulated recall and interview showed that Tan based her use of feedback on her beliefs about the importance of concise writing. That is, she was willing to accept peer feedback that could increase the conciseness of her writing while she would reject feedback that would make the writing less concise. Xiang reiterated in the baseline interview that "language accuracy should be the most important factor in good writing." In her illustration essay, she wrote, "It is almost impossible for those people sitting in front of the television, reading the newspaper, or surfing on the internet to know the truth." However, her reviewer pointed out that the sentence structure was wrong. Xiang did not use this feedback in her revision. She recalled:

I do not think the reviewer understood my sentence structure. Maybe the phrase containing "sitting", "reading", and "surfing" is too long, so he did not see the part that says "to know the truth". But I do not think there is any problem... and I am correct in using that sentence structure.

As can be seen, Xiang rejected the peer feedback if she thought it could not improve her writing accuracy, which was believed to be a crucial element of good writing.

Tan and Xiang also seemed to develop new beliefs about good expository writing due to teacher influence. For example, Tan suggested that she developed a positive view of verb reduction due to writing instruction. She pointed out: "Last time we did an exercise in class which required us to use verbs less and nouns more in writing. I think this is a good idea because I tend to do the opposite." This quote reflects Tan's favourable opinion of verb reduction under the influence of classroom instruction. Xiang was also quite aware of how teacher instruction helped contribute to her beliefs about English expository writing. She commented: "I have also internalized the qualities of good English expository writing taught by the teacher. This internalization happens if I agree with what he says." A typical example is the perceived importance of topic sentence as expressed by Xiang: "I will pay attention to what the instructor has taught in class. For example... I care a lot about whether there is a topic sentence...that's the influence of classroom instruction." This quote indicates that Xiang came to regard topic sentence as an essential element of a good expository essay probably because of writing instruction.

Classroom observation and teacher interview data suggest that teacher instruction emphasized effective language use (e.g. verb reduction) and organization (e.g. topic sentence), and such an instructional emphasis seemed to be related to 
teacher beliefs. For example, the teacher expressed the belief that "our students' writing needs to be not only accurate, but also more effective" and that "the students may not know the differences in the organization of Chinese and English essays, so the teacher has to sharpen their awareness of following the structure of the latter." These two quotes, together with the classroom observation data, suggest that the teacher's instructional focus on effective language use (e.g. verb reduction) and organization (e.g. topic sentence) could possibly be attributed to his beliefs about the importance of these two aspects.

Tan's and Xiang's respective beliefs about verb reduction and topic sentence, possibly shaped by teacher instruction and teacher beliefs, seemed to affect their selection of peer feedback. For instance, Tan integrated into her cause-andeffect essay one peer correction which changed her original phrase "papers they publish" into "their published papers". She recalled: "I knew why he made such a correction. I used a verb in 'papers they publish', and he changed the verb into an adjective. This phrase then became 'their published papers'. Our teacher has taught us this in class." Tan seemed to be willing to use this peer feedback because of her positive opinion of verb reduction as fostered by teacher instruction. In Xiang's case, her peer used a question "Is this your topic sentence?" to remind her of a lack of topic sentence in the first body paragraph of her cause-and-effect essay. She followed this feedback by adding one topic sentence to that paragraph. She recalled: "The first sentence is not the topic sentence. Oh, I do not have a topic sentence for this paragraph... Yes, I need a topic sentence here." Xiang followed this peer feedback probably because she deemed topic sentence to be an essential element for good writing, owing to teacher instruction.

\subsubsection{Beliefs about word limit}

In addition to new beliefs about good English expository writing, Tan and Xiang also regarded word limit as being important for revision. For instance, Tan stressed: "I needed to consider the factor of word limit while revising," when she talked about her revision in one interview. Similar to Tan, Xiang emphasized that it was important not to exceed the word limit: "The teacher said that he would not mark my essay if it was too long."

Tan's and Xiang's beliefs about word limit could probably be traced to the teacher's instructional emphasis on word limit and his beliefs about its importance, as revealed by classroom observation and interview data. Classroom observation showed that he repeatedly emphasized during class time that "each writing assignment should not exceed 440 words, otherwise marks would be deducted." This message was also conveyed to the students via an online learning platform used in the class. The teacher's emphasis on word limit corresponded with interview data, in which Professor Zhang advanced the rationale behind such an emphasis: "The students must learn to limit the number of words because they seldom consider the importance of conciseness. The required word limit intends to push them to polish their language repeatedly." As can be seen, Tan and Xiang attached importance to word limit probably because of teacher emphasis and related to it, his belief about the important role of word limit in encouraging students to write more concisely.

The students' beliefs about the importance of word limit, possibly related to teacher instruction and teacher beliefs, influenced their use of particular peer feedback. Tan did not follow one end comment for her cause-and-effect essay, which read "the ending paragraph seems not strong enough to support the body." She recalled, "My conclusion was actually very short because I only wrote one sentence. I decided not to revise based on the peer feedback because of the word limit, which is annoying." She further explained in the post-stimulated recall interview that she deleted part of the conclusion of her first draft for fear of exceeding the word limit. Then she reiterated that her nonuse of the peer feedback "was mainly due to the concern for the word limit," although she was "aware that the teacher had good intentions." As can be seen, the perceived importance of word limit had already affected Tan's writing of the conclusion in the first draft, and the same factor also seemed to influence her nonuse of the peer feedback related to strengthening her conclusion. Xiang did not integrate one end comment that asked her to include another paragraph to fully illustrate the thesis statement for the cause-and-effect essay: "However it would be great if you have another idea to share, ...I see you only have four paragraphs in total, and the extra paragraph may help you illustrate your thesis statement better." Xiang recalled: "I have almost reached the word limit with the paragraphs already written." In the post-stimulated recall interview, she also mentioned the same concern for word limit to account for her nonuse of the peer feedback. Such a nonuse, therefore, could be traced to Xiang's belief about word limit based on teacher instruction.

\subsubsection{Beliefs about reviewer roles}

Both students considered peer reviewers as readers of their writing and this perceived reader role affected the use of peer feedback. After experiencing the first feedback task, Tan perceived that "the audience of the writing is my peers." For one paragraph in the illustration essay, Tan's reviewer commented on the first sentence of that paragraph: "the topic sentence of this paragraph is not clear enough." Tan followed this peer feedback and changed her topic sentence to better capture the main idea of that paragraph. She recalled: "I needed to find which one was the topic sentence and actually my topic sentence was the third sentence in the paragraph.” In the post-stimulated recall interview, Tan pointed out: "If my reviewer considered that the topic sentence was not clear enough, then I needed to place my real topic sentence, the third sentence, at the beginning of this paragraph." By following the peer feedback, Tan seemed to make an effort to make her writing clearer for her reviewer, who was perceived to be her reader. Like Tan, Xiang also regarded her reviewer as the reader of her essay. For the illustration essay, Xiang wrote the sentence "Such scenes are familiar that people are waiting in queues only to buy astonishing remarkable medicines with effects on certain diseases, which later turn out to be a falsehood." Her reviewer commented on the unclear reference of "which": "here what it refers to is not clear." She thus revised the sentence into "Such scenes are familiar that people are waiting in queues only to buy astonishingly remarkable medicines which later turn out to be a falsehood." to show that "which" 
refers to medicines. She acknowledged in the stimulated recall: "The reference of "which' was unclear, so I did not express my meaning clearly to the reviewer." She further explained in the post stimulated recall interview: "The reviewer said that the reference was not clear...because in the original sentence 'which' followed 'certain diseases', but it actually referred to 'medicines'. This might cause confusion for my peer, so I revised the sentence." Like Tan, Xiang's belief about her peer's reader role enabled her to act on feedback that reflected the peer's confusion to facilitate reader's understanding.

In addition to her belief about student reviewers' reader role, Xiang also perceived her peer reviewer of the cause-andeffect essay, who was actually Tan, to be a good writer based on her evaluation of Tan's essay in a previous peer feedback task. Xiang emphasized in the post-stimulated recall interview: "I think Tan's English writing is really good." This shows that she developed a favourable opinion of Tan as a good writer after she evaluated Tan's essay.

Xiang's perception of Tan as a good writer seemed to influence her use of almost all of Tan's feedback into revision. In response to a large amount of usable peer feedback provided by Tan (i.e. 81 usable peer feedback points, mostly peer corrections), Xiang directly incorporated all of Tan's corrections into her own writing, as shown by a comparison of her first and second drafts. She recalled, "I decided to accept all the corrections and then read through the article. That is, to follow her corrections and then read the revised text." In the post stimulated recall interview, Xiang further explained:

A favourable opinion of Tan as a good writer had an influence on my use of her feedback. I decided to accept all her corrections to my text directly at the very beginning... and then to read through the revised text...I thought basically I followed all her changes.

Although the overwhelming amount of usable peer feedback received and the "accept changes" function in Microsoft Word might have led Xiang to use all of Tan's corrections, the interview data suggested that Xiang's belief about Tan's role as a good writer greatly influenced her acceptance of all peer corrections for the cause-and-effect essay.

\section{Discussion}

This study explored the degree of peer feedback use by two selected Chinese university EFL students and the influence of writing beliefs on their use of feedback. Both students were found to use peer feedback selectively, and this selective use is consistent with what has already been observed in the literature about L2 students' use of peer feedback (Paulus, 1999; Tsui \& Ng, 2000), including Chinese EFL students (Yang et al., 2006; Zhao, 2010).

While it has to be acknowledged that L2 students' use of peer feedback is subject to the influence of various factors, this study reveals learner beliefs, writing beliefs in particular, as one salient factor behind the selective use of peer feedback regardless of the students' writing proficiency. In the study, the students' self-reported beliefs about qualities of good English expository writing, about the importance of word limit and about peer reviewers' roles were found to exert a major influence. Although the relationship between beliefs and actions is complex (Barcelos, 2003), this study suggests a close relationship between the students' writing beliefs and peer feedback use. This finding extends Storch and Wigglesworth's (2010) point about the influence of learner beliefs on the use of teacher feedback to the context of peer feedback. In particular, beliefs associated with good writing, word limit and reader roles seemed to enable the students to exercise agency in peer-mediated revision by accepting or rejecting particular feedback rather than blindly following all the feedback provided.

Seen from an ecological perspective (van Lier, 2000, 2004), writing beliefs seem to be used by the students to create affordances (van Lier, 2000) to mediate feedback use for revision. According to this perspective, the meaning potential of the environment can be transformed into affordances if it is considered to be meaningful by an individual (van Lier, 2004). The two active learners in this study relied on their beliefs to transform the environment (i.e., all the usable peer feedback received) into affordances (i.e., feedback considered to be useful), and used these affordances for revision. For example, the peer feedback related to a lack of a topic sentence was an affordance to Xiang due to her newly shaped belief about the importance of a topic sentence. Consequently, she followed the feedback and performed the revision. By contrast, the comment associated with the strengthening of the conclusion was not an affordance to Tan because of her belief about the importance of not exceeding the word limit. Hence, she did not use the feedback during her revision. Writing beliefs can thus turn specific types of (but not all) usable peer feedback into affordances that were subsequently incorporated into revisions.

Moreover, some writing beliefs seem to be quite effective in creating appropriate affordances that mediated the use of peer feedback. For example, the students' pre-existing or newly shaped beliefs about qualities of good English expository writing (e.g., Tan's beliefs about concise writing and verb reduction; Xiang's beliefs about the importance of accuracy and topic sentence) could enable them to realize the usefulness of certain feedback (i.e., to regard it as affordance) and then to use it for revision according to perceived features of good writing. The students' beliefs about reviewers' reader roles could help them to perceive the affordance of the feedback considered to be offered from readers' perspective and to follow such feedback to clarify intended meaning, one of the reported benefits of peer feedback (Liu \& Hansen, 2002). The aforementioned writing beliefs were quite effective in the sense that they contributed to creating appropriate affordances that were very likely to be beneficial for peer-mediated revision.

However, there were also less effective beliefs that failed to create appropriate affordances for students to select potentially helpful peer feedback. For example, a concern for the word limit prevented the students from realizing the potential value of particular peer feedback targeting at content- or organization-related issues. Consequently, they 
refused to revise based on such feedback (e.g., Tan's refusal to strengthen the conclusion for the cause-and-effect essay; Xiang's refusal to add another idea to her writing for the cause-and-effect essay). The students thus might have lost an opportunity to revise at a macro-level, which may actually have helped to improve their writing. Xiang incorporated a very high percentage of peer feedback (i.e. 96.4\%) for the cause-and-effect essay. This percentage is much higher than the percentage of peer feedback use as identified in previous studies (Paulus, 1999; Tsui \& Ng, 2000; Yang et al., 2006; Zhao, 2010) and can be attributed to her extremely favourable opinion about Tan's role as a good writer. However, this belief was also not so effective in creating appropriate affordances in that it led her to immediately treat all of Tan's peer corrections as truly useful and incorporate them into revision without critically thinking about whether or not they were all correct.

The students' newly-shaped beliefs about good English expository writing, about the importance of word limit and about the reviewer roles, were closely related to the specific learning contexts in which they were situated. For example, their beliefs about peers' reader role were possibly shaped by participation in peer feedback activities in which one student had to adopt the role of a writer and the other had to serve as a reader. Xiang's beliefs about Tan as a good writer were probably cultivated through a previous peer feedback activity in which the former happened to evaluate the latter's writing. Furthermore, student beliefs about good English expository writing (e.g., Tan's positive views regarding verb reduction; Xiang's beliefs about topic sentence) and their concerns for the word limit were likely to have been derived from teacher instruction. These shaping influences demonstrate the contextual and dynamic nature of learner beliefs (Barcelos, 2003). Since the students themselves highlighted in the interviews the relevance of some of the above-mentioned contextual factors (i.e. teacher instruction; Xiang's participation in one previous peer review task) to their emerging beliefs, these factors, from an ecological perspective (van Lier, 2000, 2004), can be regarded as classroom affordances that mediated student writing beliefs. This is consistent with Peng's (2011) finding that learner beliefs are subject to contextual mediation of local classroom affordances. By identifying the influence of writing beliefs on peer feedback use and how these beliefs were mediated by contextual factors (particularly classroom affordances), this study shows that these contextual factors (or affordances) did not directly affect the students' peer feedback use. Rather, they interacted with such individual factors as learner beliefs to construct emerging beliefs that may mediate the students' use of peer feedback.

Among the local classroom affordances, teacher instruction emerged as an important source to develop the students' beliefs about good English writing and about the importance of word limit. The role of classroom instruction can be further traced to the teacher's beliefs about good writing (e.g. effective language use; good organization) and the importance of word limit for concise writing. This is consistent with Allen's (1996) finding that suggests the important role of teacher beliefs in helping shape students' beliefs through classroom instruction (or classroom affordances from an ecological perspective). This study thus illustrates the crucial role played by teachers as "significant others" in belief construction (Barcelos \& Kalaja, 2011), particularly in shaping learner beliefs that can mediate learner actions.

This study has demonstrated that the students' writing beliefs may be effective or less effective in creating appropriate affordances to influence their use of peer feedback, and some of these beliefs may be mediated by the local classroom affordances, with teacher instruction being one important source. This has implications for students and teachers in similar contexts. Since chances to reflect may help individuals change or refine their beliefs (Barcelos \& Kalaja, 2011), L2 students can be encouraged to reflect on the effectiveness of their beliefs and discard less effective ones that may prevent them from creating appropriate affordances so that they can utilize potentially useful peer feedback in revision. Teachers may also ask students to share their beliefs with peers through personally-created metaphors to bring about positive changes in writing beliefs (Wan, 2014). Meanwhile, with teacher beliefs and related classroom instruction playing a crucial role in students' belief construction, L2 writing teachers should be aware of this role and reflect on their own beliefs (e.g., the teacher's beliefs about the importance of word limit for concise writing or his beliefs about the significance of good organization) to ensure positive teacher influence on shaping effective student beliefs, which may be used to create appropriate affordances to guide the use of peer feedback.

\section{Conclusion}

From an ecological perspective (van Lier, 2000, 2004), this exploratory case study has taken a small step towards revealing the extent of peer feedback use of two purposefully chosen Chinese EFL university students and the influence of writing beliefs on their selective use of peer feedback. While the findings of the study cannot be overgeneralized to other learners, they shed light on how students, regardless of their writing proficiency, may use their beliefs to create affordances (van Lier, 2000, 2004) to mediate peer feedback use as purposeful and intentional agents. The findings also show how the learning context, particularly classroom instruction (and associated with it, teacher beliefs) may constitute classroom affordances to help construct some beliefs of the students. This in turn has implications for L2 teachers and students in similar contexts. That is, teachers and students need to reflect on their beliefs and ensure that these beliefs can positively influence the latter's creation of appropriate affordances to contribute to the selection of useful peer feedback in learning to write.

This study was exploratory in nature and involved selected students in a particular setting. Hence, future studies may examine the potential role of writing beliefs in influencing L2 students' use of peer feedback or more generally, in influencing their learning to write in different settings across different student populations. Moreover, writing beliefs were self-reported through interviews in this study. In future studies, both interviews and other sources of data (e.g. observation) may be used to gauge learner beliefs. Thirdly, this study showed that classroom context might help shape writing beliefs that affected the students' use of peer feedback. In other words, contextual factors in this study (i.e. local 
classroom affordances) interacted with writing beliefs to exert an influence. What can be further explored is how writing beliefs as an individual factor may interact with various contextual factors (including classroom affordances) to mediate L2 students' performance in peer feedback tasks and their learning to write. Case studies adopting a contextual approach (Barcelos, 2003) may be useful in this respect. Lastly, teacher beliefs and instruction in this study seem to be quite successful in constructing student beliefs that could be used to meditate the use of peer feedback. However, the underlying reason of the strong influence of teacher beliefs and instruction was not further explored. Therefore, future studies may investigate why and how teacher beliefs and instruction, as a source of classroom affordance, can contribute to students' internalization of new beliefs that may be utilized to mediate learning to write. Although more studies are necessary, this exploratory study has attempted to use an ecological perspective (van Lier, 2000, 2004) and a contextual approach (Barcelos, 2003) to reveal the influence of writing beliefs on L2 students' use of peer feedback and to chart directions for future research.

\section{References}

Allen, L. (1996). The evolution of a learner's beliefs about language learning. Carleton Papers in Applied Language Studies, 13, 67-80. http://dx.doi.org/10.1007/978-1-4020-4751-0_1

Barcelos, A. M. F. (2003). Researching beliefs about SLA: A critical review. In P. Kalaja \& A. M. F. Barcelos (Eds.) Beliefs about SLA: New Research Approaches (pp. 7-33). Dordrecht: Kluwer Academic Publishers.

Barcelos, A. M. F. \& Kalaja, P. (2011). Introduction to Beliefs about SLA Revisited. System, 39, $281-289$. http://dx.doi.org/10.1016/j.system.2011.07.001

Dornyei, Z. (2005). The Psychology of the Language Learner: Individual Differences in Second Language Acquisition. Mahwah, NJ: Lawrence, Erlbaum.

Ellis, R. (2010). A framework for investigating oral and written corrective feedback. Studies in Second Language Acquisition 32: 335--349. http://dx.doi.org/10.1017/S0272263109990544

Gass, S. M. \& Mackey, A. (2000). Stimulated Methodology in Second Language Research. Mahwah: Lawrence Erlbaum Associates.

Glaser, B. G. \& Strauss, A. L. (1967). The Discovery of Grounded Theory: Strategies for Qualitative Research. New York: Aldine.

Hyland, F. (1998). The Impact of Teacher Written Feedback on Individual Writers. Journal of Second Language Writing 7: 255--286. http://dx.doi.org/10.1016/s1060-3743(98)90017-0

Hyland, F. (2010) Future directions on feedback in second language writing: Overview and future research agenda. International Journal of English Studies, 10, 171-182.

Kim, T. Y. (2013). An activity theory analysis of second language motivational self-system: Two Korean immigrants' ESL learning. Asia-Pacific Education Researcher, 22, 459-471. http://dx.doi.org/10.1007/s40299-012-0045-x

Lee, I. (2014). Feedback in writing: Issues and challenges. Assessing Writing, 19, 1-5. http://dx.doi.org/10.1016/j.asw.2013.11.009

Lei, X. (2008) Exploring a sociocultural approach to writing strategy research: Mediated actions in writing activities. Journal of Second Language Writing, 17, 217-236. http://dx.doi.org/10.1016/j.jslw.2008.04.001

Lincoln, Y. S. \& Guba, E. G. (1985). Naturalistic Inquiry. Beverly Hills: Sage.

Liu, J., \& Hansen, J. G. (2002). Peer Response in Second Language Writing Classrooms. Ann Arbor, MI: The University of Michigan Press.

Lockhart, C. \& Ng, P. (1995). Analysing talk in peer response groups: Stances, functions and content. Language Learning, 45, 605-625. http://dx.doi.org/10.1111/j.1467-1770.1995.tb00456.x

Min, H. T. (2003). Why peer comments fail. English Teaching and Learning, 27, 85-103.

Min, H. T. (2006). The effects of trained peer review on EFL students' revision types and writing quality. Journal of Second Language Writing,15, 118-141. http://dx.doi.org/10.1016/j.jslw.2006.01.003

Navarro, D., \& Thornton, K. (2011). Investigating the relationship between belief and action in self-directed language learning. System, 39, 290-301. http://dx.doi.org/10.1016/j.system.2011.07.002

Paulus, T. (1999). The effect of peer and teacher feedback on student writing. Journal of Second Language Writing, 8, 265-289. http://dx.doi.org/10.1016/s1060-3743(99)80117-9

Peng, J. E. (2011). Changes in language learning beliefs during a transition to tertiary study: The mediation of classroom affordances. System, 39, 314--324. http://dx.doi.org/10.1016/j.system.2011.07.004

Porte, G. (1997). The etiology of poor second language writing: The influence of perceived teacher preferences on second language revision strategies. Journal of Second Language Writing, 6, 61--78. http://dx.doi.org/10.1016/s10603743(97)90006-0

Riley, P. (1997). The guru and the conjurer: Aspects of counselling for self-access. In P. Benson \& P. Voller (Eds.) Autonomy and Independence in Language Learning (pp. 114-131). New York: Longman. 


Riley, P. (2009). Shifts in beliefs about second language learning. RELC Journa,l 40, $102-124$.
http://dx.doi.org/10.1177/0033688208101448

Storch, N., \& Wigglesworth, G. (2010). Students' engagement with feedback on writing: The role of learner agency/beliefs. In R. Batstone (Ed.) Sociocognitive Perspectives on Language Use and Language Learning (pp.167185). New York: Oxford University Press.

Tsui, A., \& Ng, M. (2000). Do secondary L2 writers benefit from peer comments?. Journal of Second Language Writing, 9, 147-170. http://dx.doi.org/10.1016/s1060-3743(00)00022-9

van Lier, L. (2000). From input to affordance: Social interactive learning from an ecological perspective. In J. P. Lantolf (Ed.) Sociocultural Theory and Second Language Learning 245-259. Oxford, UK: Oxford University Press.

van Lier, L. (2004). The Ecology and Semiotics of Language Learning: A Sociocultural Perspective. Norwell, MA: Kluwer. http://dx.doi.org/10.1007/1-4020-7912-5

Victori, M. (1999). An analysis of writing knowledge in EFL composing: A case study of two effective and two less effective writers. System, 27, 537-555. http://dx.doi.org/10.1016/s0346-251x(99)00049-4

Wan, W. (2014). Constructing and developing ESL students' beliefs about writing through metaphor: An exploratory study. Journal of Second Language Writing, 23, 53-73. http://dx.doi.org/10.1016/j.jslw.2014.01.002

Wenden, A. (1987). How to be a successful language learner: Insights and prescriptions from second language learners. In A. Wenden \& J. Rubin (Eds.) Learner Strategies in Language Learning (pp. 103-117). Hemel Hempstead: Prentice Hall.

White, C. (1999). Expectations and emergent beliefs of self-instructed language learners. System, 27, 443-458. http://dx.doi.org/10.1016/s0346-251x(99)00044-5

Woods, D. (2003). The social construction of beliefs in the language classroom. In P. Kalaja \& A. M. F. Barcelos (Eds.) Beliefs about SLA: New research approaches (pp. 201-230). Dordrecht: Kluwer Academic Publishers. http://dx.doi.org/10.1007/978-1-4020-4751-0_9

Yang, M., Badger, R., \& Yu, Z. (2006). A comparative study of peer and teacher feedback in a

Chinese EFL writing class. Journal of Second Language Writing, 15,179-200.

http://dx.doi.org/10.1016/j.jslw.2006.09.004

Zhao, H. (2010). Investigating learners' use and understanding of peer and teacher feedback on writing: A comparative study in a Chinese English writing classroom. Assessing writing, 15, 3-17. http://dx.doi.org/10.1016/j.asw.2010.01.002 